\title{
The over-optimistic portrayal of life-supporting treatments in newspapers and on the Internet: a cross-sectional study using extra-corporeal membrane oxygenation as an example
}

Yen-Yuan Chen ${ }^{1,2}$, Likwang Chen ${ }^{3}$, Yu-Hui Kao ${ }^{4}$, Tzong-Shinn Chu ${ }^{2,5}$, Tien-Shang Huang ${ }^{1,6^{*}}$ and Wen-Je Ko ${ }^{7,8}$

\begin{abstract}
Background: Extra-corporeal membrane oxygenation has been introduced to clinical practice for several decades. It is unclear how internet and newspapers portray the use of extra-corporeal membrane oxygenation. This study were: (1) to quantify the coverage of extra-corporeal membrane oxygenation use in newspapers and on the Internet; (2) to describe the characteristics of extra-corporeal membrane oxygenation users presented in newspaper articles and the Internet web pages in comparison with those shown in extra-corporeal membrane oxygenation studies in Taiwan; and (3) to examine the survival rates of extra-corporeal membrane oxygenation users presented in newspaper articles and the Internet web pages in comparison with those in Taiwan and in the Extracorporeal Life Support Registry Report International Summary for January 2014.
\end{abstract}

Methods: All issues of Taiwan's four major newspapers from 2006 to 2010 were reviewed. In October 2011, a search of Internet web pages was performed based on the subjects of "yeh-ko-mo" (extra-corporeal membrane oxygenation in Traditional Chinese), "ECMO", and "extra-corporeal membrane oxygenation." All the Internet web pages and newspaper articles recounting the use of extra-corporeal membrane oxygenation were reviewed. The information, such as patient characteristic and the status at hospital discharge, was collected.

Results: The survival rate of extra-corporeal membrane oxygenation use shown on the Internet (83.97\%) was significantly higher than all the survival rates reported in Taiwan's literature $(p<.01)$ and in the Extracorporeal Life Support Registry Report International Summary for January $2014(p<.01)$. In addition, the survival rate of extra-corporeal membrane oxygenation use shown in newspapers (61.54\%) was significantly higher than the average survival rate (43\%) reported in Taiwan's literature, the pediatric average survival rate (51\%), and the adult average survival rate (47\%) in the Extracorporeal Life Support Registry Report International Summary for January 2014.

Conclusions: Internet and newspapers both showed over-optimistic survival to hospital discharge for patients sustained by extra-corporeal membrane oxygenation. Internet was more likely to provide optimistic information for aggressive life-supporting treatments such as extra-corporeal membrane oxygenation than newspapers as indicated by survival to hospital discharge.

Keywords: Life-supporting treatment, Extra-corporeal membrane oxygenation, Media, Internet, Newspaper

\footnotetext{
* Correspondence: huangts@ntu.edu.tw

'Department of Social Medicine, National Taiwan University College of

Medicine, No. 1, Rd. Ren-Ai sec. 1, Taipei 10051, Taiwan

${ }^{6}$ Department of Internal Medicine, National Taiwan University Hospital,

No. 7, Rd. Chong-Shan S, Taipei 10002, Taiwan

Full list of author information is available at the end of the article
} 


\section{Background}

Extra-corporeal membrane oxygenation (ECMO) is a technique for providing cardiac and respiratory support to patients by using a modified heart-lung machine. ECMO can support life for days to weeks, permitting treatment and recovery during severe cardiac or respiratory failure. According to the Extracorporeal Life Support Registry Report International Summary for January 2014 (ECLS 2014), the annual number of patients supported by ECMO increased from 1,644 in 1990 to 4,357 in 2013. From 1990 to 2013, 58,842 patients received ECMO for cardiac or respiratory failure, or received ECMO-assisted cardiopulmonary resuscitation (CPR), with 35,307 (60\%) surviving to hospital discharge. Of the 58,842 patients supported by ECMO, 33,412 (56.78\%) were neonatal patients, who have the highest rates of immediate survival after ECMO use, and the highest rates of survival to hospital discharge, compared with adult and pediatric patients. Of the 5,146 adult patients who received ECMO because of respiratory failure, 2,905 (56.45\%) survived to hospital discharge. Of the 4,042 patients who received ECMO because of cardiac failure, 1,636 (40.48\%) survived to hospital discharge. The average rate of adult ECMO patients surviving to hospital discharge was $46.96 \%$ [1].

Taiwan has become one of the major countries for ECMO use. In 2010, 1,126 Taiwanese patients received ECMO support [2]. In six Taiwanese studies reporting the survival of ECMO users with cardiac failure, the survival rates at hospital discharge ranged from $27.78 \%$ to $64 \%$ [3-8], with an approximate average survival rate of 44.03\%. A study by Chen et al. in 2011 reported a 31.58\% survival rate of ECMO users with respiratory failure (Table 1) [6].
The mass media, such as newspapers and the Internet, can have a substantial influence on the public's attitudes and behaviors. For example, newspapers and the Internet provide readers with information on advances in medical technology, and the use of life-supporting treatments (LST). The information in newspapers and on the Internet may thus influence the decision-making of patients/family members regarding the request for an aggressive LST such as ECMO [9].

The purpose of our study was to examine the portrayal of ECMO use by Taiwan's four major newspapers and the Internet web pages written in traditional Chinese. The specific aims were to: (1) quantify the coverage of ECMO use on newspapers and the Internet; (2) describe the characteristics of ECMO users presented in newspaper articles and the Internet web pages in comparison with those shown in ECMO studies in Taiwan; and (3) determine the survival rates of ECMO users presented in newspaper articles and the Internet web pages in comparison with those in ECMO studies in Taiwan and in the ECLS 2014.

\section{Methods}

\section{Selection of stories}

Some ECMO patients were featured in newspapers only (patients in newspapers), or on the Internet only (patients on the Internet). Those both featured on newspapers and the Internet were patients both in newspapers and on the Internet. Patients were defined as the ECMO patients either reported in newspapers or in the Internet. Therefore, patients are equal to the total of patients in newspapers, patients on the Internet, and patients both in newspapers and on the Internet.

Table 1 Studies conducted in Taiwan for reporting the survival rates for extra-corporeal membrane oxygenation use

\begin{tabular}{|c|c|c|c|c|c|c|}
\hline & Location & Primary reason & Age $($ Mean \pm SD) & Gender (F/M) & $\begin{array}{l}\text { Alive/Dead at } \\
\text { hospital discharge }\end{array}$ & Survival rate \\
\hline \multirow[t]{2}{*}{ Chung SY et al., 2012 [8] } & A & CF & $51.8 \pm 20.5$ & $30 / 104$ & $57 / 77$ & $42.50 \%$ \\
\hline & & RF & NA & NA & NA & NA \\
\hline \multirow[t]{2}{*}{ Hsu KH et al., 2011 [7] } & B & CF & $29.7 \pm 18.7$ & $46 / 29$ & $48 / 27$ & $64 \%$ \\
\hline & & RF & NA & NA & NA & NA \\
\hline \multirow[t]{2}{*}{ Chen YC et al., 2011 [6] } & A & $\mathrm{CF}$ & $47 \pm 2^{a}$ & $40 / 62$ & $36 / 44$ & $45 \%$ \\
\hline & & RF & NA & NA & $6 / 13$ & $31.58 \%$ \\
\hline \multirow[t]{2}{*}{ Chou NK et al., 2010 [5] } & B & CF & $42.3 \pm$ Unknown $^{\mathrm{a}}$ & $5 / 35$ & $21 / 19$ & $52.50 \%$ \\
\hline & & RF & NA & NA & NA & NA \\
\hline \multirow[t]{2}{*}{ Hsu PS et al., 2010 [4] } & C & CF & $63.0 \pm 15.7$ & $15 / 36$ & $17 / 34$ & $33.33 \%$ \\
\hline & & RF & NA & NA & NA & NA \\
\hline \multirow[t]{2}{*}{ Ko WJ et al., 2002 [3] } & $\mathrm{B}$ & CF & $56.8 \pm 15.9$ & $28 / 48$ & $20 / 52$ & $27.78 \%$ \\
\hline & & RF & NA & NA & NA & NA \\
\hline
\end{tabular}

Abbreviations list: $C F$ cardiac failure, $R F$ respiratory failure, $S D$ standard deviation, $F / M$ female/male, $N A$ not applicable, $A$ medical center $A, B$ medical center $B$, $C$ medical center $C$.

${ }^{\text {a }}$ The values were the median of patients' ages. 
A newspaper article describing a case of ECMO patient was a story in newspaper. An Internet web page describing a case of ECMO patient was a story on the Internet. Each single patient in newspaper or patient on the Internet could appear in several newspaper articles and Internet web pages, thus resulting in numerous stories in newspapers and stories on the Internet (Figure 1).

All issues of Taiwan's four major newspapers, the Liberty Times, the Apple Daily, the China Times and the United Daily News, from 2006 to 2010, were searched and reviewed, and the headlines and texts of the newspaper articles on ECMO use were counted as a story in newspaper. In October 2011, a search of Internet web pages was performed using "yeh-ko-mo" (ECMO in traditional Chinese medicine), "ECMO," and "extra-corporeal membrane oxygenation" as search terms. Each single Internet web page recounting ECMO use was counted as a story on the Internet.

\section{Data collection}

For each story on the Internet and story in newspaper, the following information was collected: age, sex, the location of the hospital of ECMO use (rural or urban area), the level of the hospital (medical center or nonmedical center, as classified by Taiwan Joint Commission

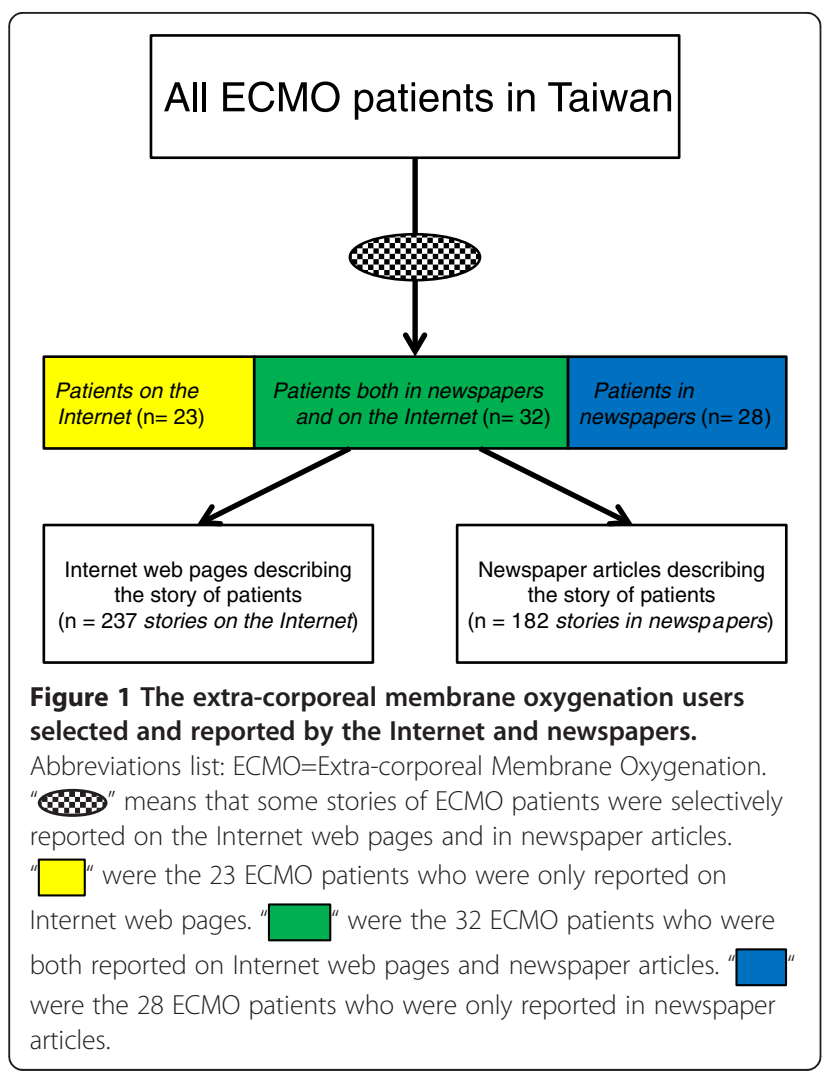

on Hospital Accreditation), the duration of ECMO use, the duration of intensive care unit stay, the duration of hospital stay, the status at hospital discharge, and the primary reason for ECMO use.

\section{Statistical analysis}

The continuous variables of patients, patients on the Internet, patients in newspapers, stories on the Internet, and stories in newspapers were compared with those from studies on ECMO use in Taiwan published in journals indexed in the Sciences Citation Index [3-8], and the ECLS 2014 [1], using one-sample $t$-tests. The associations between the characteristics of patients and patients on the Internet, between patients and patients in newspapers, and between patients and stories, were evaluated using Student's $t$-tests or Chi-squared tests. The survival rates of patients, patients on the Internet, patients in newspapers, stories on the Internet, and stories in newspapers were compared with those derived from the ECMO studies in Taiwan and the ECLS 2014, using one-sample $t$-tests. All statistical analyses were performed using the software package STATA MP 11.0 for Windows PC.

\section{Results}

\section{Comparison of characteristics}

Overall, we collected 419 stories (83 patients): 237 stories (55 patients on the Internet) from the Internet web pages and 182 stories (60 patients on newspapers) from the newspaper articles (Figure 1 and Table 2). Thirty-two of the ECMO patients appeared both in the newspaper articles and on the Internet web pages. Of the 182 stories in newspapers (patients in newspapers) collected from the four major newspapers, 12 (4), 23 (7), 75 (22), 42 (16), and 30 (11) stories in newspapers (patients in newspapers) were from the years 2006, 2007, 2008, 2009, and 2010, respectively.

Because the average ages of the ECMO patients in the studies by Chen et al. and Chou et al. were unavailable [5,6], and because some of the ECMO patients in the study by Chen et al. were also included in the study by Chung et al., we excluded these two studies from our analyses. In the remaining four studies $[3,4,7,8]$, the average age of the 336 patients was 49.70 years. Of these patients, 119 (35.42\%) were women. The rates of survival to hospital discharge for the ECMO users ranged from $27.78 \%$ to $64 \%$, with an average survival rate of $42.77 \%$.

The average ages of the 419 stories and 83 patients were $31.34( \pm 21.77)$ years and $31.68( \pm 22.72)$ years, respectively. These ages were significantly lower than the average ages of the patients in the four studies $(p<.01)$. We noted that $38.44 \%$ of the 419 stories and $36.71 \%$ of the 83 patients were women. These values showed nonsignificant differences from the percentages of women in the four studies. 
Table 2 Comparison of the characteristics and the rates of surviving to hospital discharge

\begin{tabular}{|c|c|c|c|c|c|c|c|c|c|}
\hline & $\begin{array}{l}\text { Stories on } \\
\text { the Internet } \\
(\mathrm{n}=237)\end{array}$ & $p$ value $^{a}$ & $\begin{array}{l}\text { Patients on } \\
\text { the Internet } \\
(\mathrm{n}=55)\end{array}$ & $p$ value $^{\mathrm{b}}$ & $\begin{array}{l}\text { Patients } \\
(\mathrm{n}=83)\end{array}$ & $p$ value $^{c}$ & $\begin{array}{l}\text { Patients in } \\
\text { newspapers } \\
(n=60)\end{array}$ & $p$ value $^{d}$ & $\begin{array}{l}\text { Stories in } \\
\text { newspapers } \\
(\mathrm{n}=182)\end{array}$ \\
\hline $\mathrm{Age}^{\mathrm{e}}$ & $33.37 \pm 21.62$ & 0.71 & $34.65 \pm 23.75$ & 0.47 & $31.68 \pm 22.72$ & 0.63 & $29.88 \pm 21.31$ & 0.73 & $28.75 \pm 21.75$ \\
\hline $\begin{array}{l}\text { Length of ECMO } \\
\text { use by day }\end{array}$ & $15.66 \pm 26.95$ & 0.34 & $11.66 \pm 18.79$ & 0.74 & $10.57 \pm 16.08$ & 0.55 & $12.37 \pm 17.95$ & 0.86 & $12.87 \pm 18.91$ \\
\hline $\begin{array}{l}\text { Length of ICU } \\
\text { stay by dayg }\end{array}$ & $16.90 \pm 16.91$ & 0.70 & $15.64 \pm 17.55$ & 0.60 & $13.67 \pm 15.80$ & 0.93 & $13.36 \pm 13.83$ & 0.75 & $14.21 \pm 14.04$ \\
\hline $\begin{array}{l}\text { Length of hospital } \\
\text { stay by day }\end{array}$ & $38.69 \pm 50.61$ & 0.64 & $43.13 \pm 64.68$ & 0.60 & $36.86 \pm 56.41$ & 0.57 & $31.49 \pm 36.88$ & 0.97 & $31.72 \pm 38.19$ \\
\hline Gender ${ }^{i}$ & & 0.51 & & 0.53 & & 0.55 & & 0.95 & \\
\hline Male & $146(63.76 \%)$ & & 35 (68.63\%) & & $50(63.29 \%)$ & & 35 (58.33\%) & & $107(58.79 \%)$ \\
\hline Female & 83 (36.24\%) & & $16(31.37 \%)$ & & $29(36.71 \%)$ & & 25 (41.67\%) & & $75(41.21 \%)$ \\
\hline Hospital location & & 0.22 & & 0.34 & & 0.99 & & 0.98 & \\
\hline Urban & $190(80.17 \%)$ & & 40 (72.73\%) & & $54(65.06 \%)$ & & $39(65 \%)$ & & $118(64.84 \%)$ \\
\hline Rural & 47 (19.83\%) & & 15 (27.27\%) & & 29 (34.94\%) & & $21(35 \%)$ & & $64(36.16 \%)$ \\
\hline Level of hospitalj & & 0.12 & & 0.55 & & 0.90 & & 0.69 & \\
\hline Medical center & 168 (70.89\%) & & $33(60 \%)$ & & 45 (54.88\%) & & $33(55.93 \%)$ & & $106(58.89 \%)$ \\
\hline Non-medical center & 69 (29.11\%) & & $22(40 \%)$ & & $37(45.12 \%)$ & & $26(44.07 \%)$ & & 74 (41.11\%) \\
\hline $\begin{array}{l}\text { Primary reason } \\
\text { for ECMO use }\end{array}$ & & 0.43 & & 0.89 & & 0.95 & & 0.99 & \\
\hline Cardiac & 127 (53.59\%) & & $26(47.27 \%)$ & & 40 (48.19\%) & & 30 (50\%) & & $93(51.10 \%)$ \\
\hline Pulmonary & 95 (40.08\%) & & $23(41.82 \%)$ & & 32 (38.55\%) & & $23(38.33 \%)$ & & 68 (37.36\%) \\
\hline Others & $15(6.33 \%)$ & & $6(10.91 \%)$ & & $11(13.25 \%)$ & & 7 (11.67\%) & & $21(11.54 \%)$ \\
\hline $\begin{array}{l}\text { Status at hospital } \\
\text { discharge }\end{array}$ & & 0.31 & & 0.28 & & 0.68 & & 0.48 & \\
\hline Alive & 199 (83.97\%) & & $43(78.18 \%)$ & & $58(69.88 \%)$ & & 40 (66.67\%) & & $112(61.54 \%)$ \\
\hline Dead & 38 (16.03\%) & & 12 (21.82\%) & & $25(30.12 \%)$ & & 20 (33.33\%) & & 70 (38.46\%) \\
\hline
\end{tabular}

Abbreviations list: ECMO extra-corporeal membrane oxygenation, ICU intensive care unit.

Interpretations of "Status at hospital discharge": $58(69.88 \%)$ patients survived to hospital discharge, and 43 (78.18\%) patients on the Internet survived to hospital discharge. The $p$ value (0.28) is not significant; 43 (78.18\%) patients on the Internet survived to hospital discharge, and 199 (83.97\%) stories on the Internet survived to hospital discharge. The $p$ value $(0.31)$ is not significant.

${ }^{a}$ The $p$ value of the comparisons between stories on the Internet $(n=237)$ and patients on the Internet $(n=55)$.

${ }^{\mathrm{b}}$ The $p$ value of the comparisons between patients on the Internet $(\mathrm{n}=55)$ and patients $(\mathrm{n}=83)$.

${ }^{c}$ The $p$ value of the comparisons between patients $(n=83)$ and patients in newspapers $(n=60)$.

${ }^{\mathrm{d}}$ The $p$ value of the comparisons between patients in newspapers $(\mathrm{n}=60)$ and stories in newspapers $(\mathrm{n}=182)$.

"'Age": stories on the Internet $=6$ missing values; patients on the Internet $=3$ missing values; patients $=3$ missing values.

" "Length of ECMO use by day": stories on the Internet $=20$ missing values; patients on the Internet = 8 missing values; patients = 11 missing values; patients in newspapers $=5$ missing values; stories in newspapers $=9$ missing values.

g"Length of ICU stay by day": stories on the Internet = 92 missing values; patients on the Internet = 22 missing values; patients = 35 missing values; patients in newspapers $=24$ missing values; stories in newspapers $=66$ missing values.

h"Length of hospital stay by day": stories on the Internet = 71 missing values; patients on the Internet = 15 missing values; patients = 20 missing values; patients in newspapers $=13$ missing values; stories in newspapers $=28$ missing values.

i"Gender": stories on the Internet $=8$ missing values; patients on the Internet $=4$ missing values; patients $=4$ missing values.

j"Level of hospital": patients $=1$ missing value; patients in newspapers $=1$ missing value; stories in newspapers $=2$ missing values.

Myocarditis (121 stories, 22 patients), acute respiratory distress syndrome (86 stories, 13 patients), and acute myocardial infarction (44 stories, 12 patients) were the three leading primary causes of the need for ECMO. Patients with longer durations of ECMO use, longer durations in an intensive care unit, or cardiac failure as the primary reason for initiating ECMO were likely to have a greater number of stories both in newspapers and on the Internet than other patients. The numbers of stories and patients surviving to hospital discharge were 311 (74.22\%) and 58 $(69.88 \%)$, respectively.

\section{Comparison of survival rates}

We compared the survival rate of the 83 patients with that of the 55 patients on the Internet and with that of the 60 patients in newspapers. We also compared the survival rate of the 55 patients on the Internet with that of the 237 stories on the Internet, and compared the 
Table 3 Comparison of the characteristics and the rates of surviving to hospital discharge between "Patients" and "Stories"

\begin{tabular}{|c|c|c|c|c|c|}
\hline & $\begin{array}{l}\text { Stories on the } \\
\text { Internet }(n=237)\end{array}$ & $p$ value $^{a}$ & Patients $(n=83)$ & $p$ value ${ }^{b}$ & $\begin{array}{l}\text { Stories in newspapers } \\
(\mathrm{n}=182)\end{array}$ \\
\hline $\mathrm{Age}^{\mathrm{c}}$ & $33.37 \pm 21.62$ & 0.55 & $31.68 \pm 22.72$ & 0.32 & $28.75 \pm 21.75$ \\
\hline Length of ECMO use by day ${ }^{d}$ & $15.65 \pm 26.95$ & 0.13 & $10.57 \pm 16.08$ & 0.37 & $12.87 \pm 18.91$ \\
\hline Length of ICU stay by day ${ }^{e}$ & $16.90 \pm 16.91$ & 0.24 & $13.67 \pm 15.80$ & 0.83 & $14.21 \pm 14.04$ \\
\hline Length of hospital stay by day ${ }^{f}$ & $38.69 \pm 50.61$ & 0.81 & $36.86 \pm 56.41$ & 0.44 & $31.72 \pm 38.19$ \\
\hline Gender $^{\mathrm{g}}$ & & 0.94 & & 0.50 & \\
\hline Male & $146(63.76 \%)$ & & $50(63.29 \%)$ & & 107 (58.79\%) \\
\hline Female & $83(36.24 \%)$ & & $29(36.71 \%)$ & & $75(41.21 \%)$ \\
\hline Hospital location & & $<0.01$ & & 0.97 & \\
\hline Urban & $190(80.17 \%)$ & & $54(65.06 \%)$ & & $118(64.84 \%)$ \\
\hline Rural & $47(19.83 \%)$ & & 29 (34.94\%) & & $64(36.16 \%)$ \\
\hline Level of hospital ${ }^{h}$ & & $<0.01$ & & 0.54 & \\
\hline Medical center & $168(70.89 \%)$ & & $45(54.88 \%)$ & & $106(58.89 \%)$ \\
\hline Non-medical center & 69 (29.11\%) & & $37(45.12 \%)$ & & $74(41.11 \%)$ \\
\hline Primary reason for ECMO use & & 0.14 & & 0.88 & \\
\hline Cardiac & 127 (53.59\%) & & 40 (48.19\%) & & $93(51.10 \%)$ \\
\hline Pulmonary & $95(40.08 \%)$ & & $32(38.55 \%)$ & & $68(37.36 \%)$ \\
\hline Others & $15(6.33 \%)$ & & $11(13.25 \%)$ & & $21(11.54 \%)$ \\
\hline Status at hospital discharge & & $<0.01$ & & 0.19 & \\
\hline Alive & 199 (83.97\%) & & $58(69.88 \%)$ & & $112(61.54 \%)$ \\
\hline Dead & $38(16.03 \%)$ & & $25(30.12 \%)$ & & $70(38.46 \%)$ \\
\hline
\end{tabular}

Abbreviations list: ECMO extra-corporeal membrane oxygenation, ICU intensive care unit.

Interpretations of "Status at hospital discharge": 58 (69.88\%) patients survived to hospital discharge, and 199 (83.97\%) stories on the Internet survived to hospital discharge. The $p$ value $(<0.01)$ is significant. That is, the survival of ECMO patients on the Internet is over-optimistic.

${ }^{a}$ The $p$ value of the comparisons between patients $(n=83)$ and stories on the Internet $(n=237)$.

${ }^{\mathrm{b}}$ The $p$ value of the comparisons between patients $(\mathrm{n}=83)$ and stories in newspapers $(\mathrm{n}=182)$.

"Age": stories on the Internet $=6$ missing values; patients $=3$ missing values.

d"Length of ECMO use by day": stories on the Internet $=20$ missing values; patients $=11$ missing values; stories in newspapers $=9$ missing values

e"Length of ICU stay by day": stories on the Internet = 92 missing values; patients $=35$ missing values; stories in newspapers $=66$ missing values.

${ }^{\mathrm{f}}$ "Length of hospital stay by day": stories on the Internet $=71$ missing values; patients $=20$ missing values; stories in newspapers $=28$ missing values.

" "Gender": stories on the Internet $=8$ missing values; patients $=4$ missing values.

h"Level of hospital": patients = 1 missing value; stories on the Internet $=1$ missing value; stories in newspaprts $=2$ missing values

survival rate of the 60 patients in newspapers with that of the 182 stories in newspapers (Tables 2 and 3). Although the average survival rate of the 55 patients on the Internet was $8.3 \%$ higher than that of the 83 patients $(p=.28)$, and the average survival rate of the 237 stories on the Internet was $5.79 \%$ higher than that of the 55 patients on the Internet $(p=.31)$, these differences were not statistically significant. Similarly, the difference between the survival rate of the 83 patients and that of the 60 patients in newspapers $(p=.68)$, and the difference between the survival rate of the 60 patients in newspapers and that of the stories in newspapers $(p=.48)$, were not statistically significant (Table 2).

Subsequently, we compared the survival rate of the 83 patients with that of the 237 stories on the Internet, and with that of the 182 stories on newspapers (Table 3). The average survival rate of the 237 stories on the Internet was significantly higher than that of the 83 patients $(p<.01)$. Although the average survival rate of the 182 stories in newspapers was $8.34 \%$ lower than that of the 83 patients, this difference was not statistically significant $(p=.19)$. We identified that the Internet web pages were more likely to report a higher rate of survival to hospital discharge following ECMO use than newspaper articles.

We compared the survival rates of the 83 patients, 419 stories, 55 patients on the Internet, 60 patients in newspapers, 237 stories on the Internet, and 182 stories in newspapers with those of the patients in the ECMO studies in Taiwan and the ECLS 2014 (Figure 2). The average survival rate of the 419 stories (74.22\%) was significantly higher than the highest survival rate in the four studies and the ECLS $2014(p<.01)$. Although the survival rate of the 83 patients (69.88\%) was higher than the highest survival rate reported in Taiwan (64\%), this difference did not achieve statistical significance $(p=.25)$. The average survival rate of the 83 patients showed 


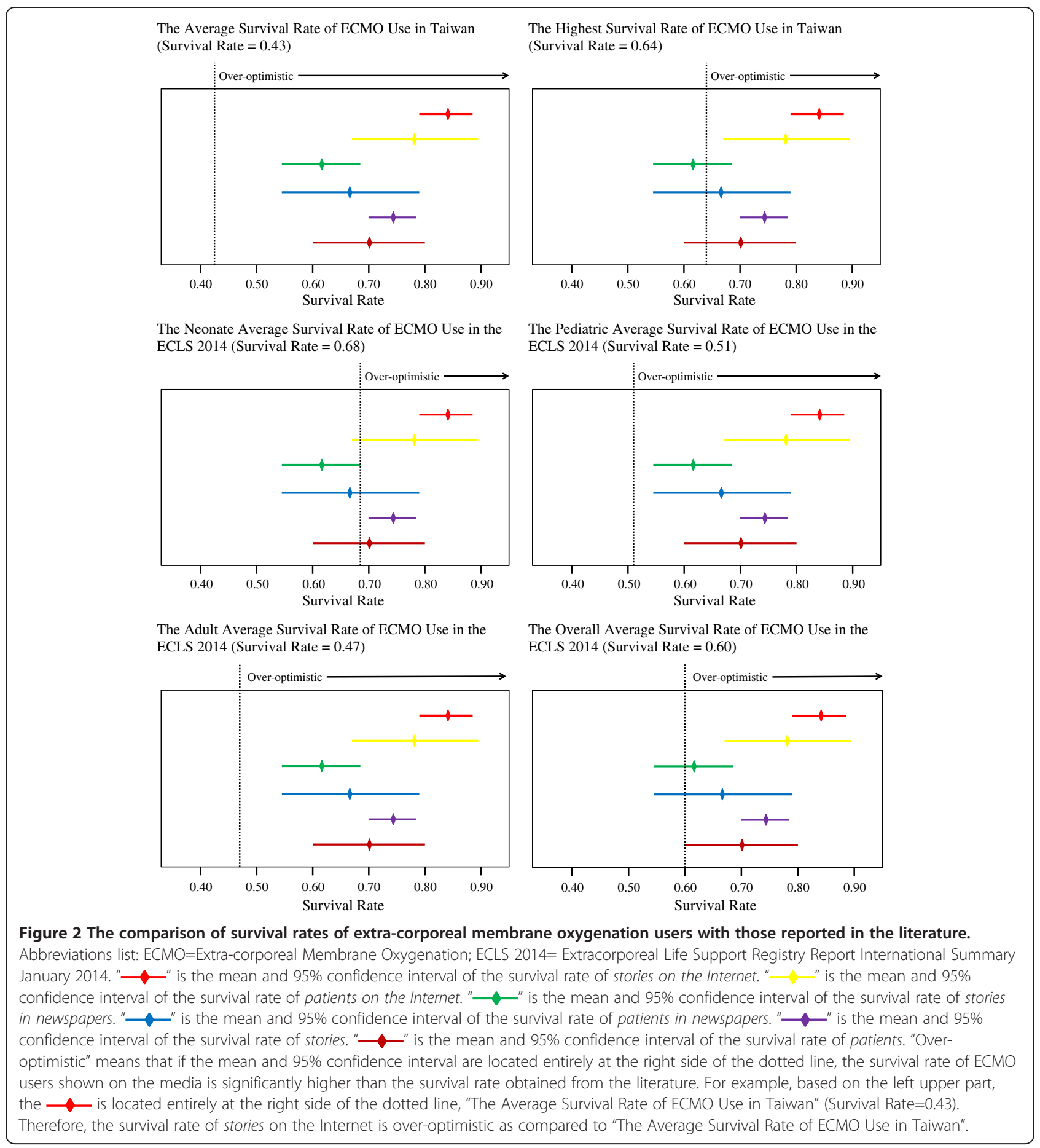

non-significant differences from the average survival rate of all ECMO patients (60\%) reported in the ECLS $2014(p=.05)$.

The survival rate of the 237 stories on the Internet was significantly higher than the survival rates reported in the ECMO studies in Taiwan $(p<.01)$ and in the ECLS $2014(p<.01)$. However, the survival rate of the 182 stories in newspapers was not significantly higher than the highest survival rate of ECMO use in Taiwan $(p=.50)$, and the average survival rate of ECMO use for all patients in the ECLS 2014 ( $p=.67)$ (Figure 2 and Table 3).

The majority of the 419 stories and 83 patients were adult patients, whereas the majority of the patients from whom data were collected in the ECLS 2014 were neonatal patients. Therefore, we also compared the survival rates presented in newspaper articles and Internet web pages 
with the average survival rate of the adult ECMO patients reported in the ECLS 2014 (Figure 2). The survival rates of the 419 stories and 83 patients were both significantly higher than the average survival rate of the adult ECMO patients $(46.96 \%)$ reported in the ECLS $2014(p<.01)$.

\section{Discussion}

Novel LSTs such as ECMO typically attract considerable media attention in Taiwan [9]. In this study, we investigated the medical information on ECMO use presented in newspapers and on Internet web pages. We identified that: 1) Internet web pages were more likely to reproduce or duplicate the survival of ECMO patients than newspaper articles; and 2) the survival rates for ECMO use reported in newspapers and on Internet web pages were both overoptimistic as compared to those published in journals and the ECLS 2014.

\section{Media and life-supporting treatment}

In 1996, Diem et al. investigated the depiction of CPR in three popular television medical dramas in the United States, and observed that the medical information, such as the immediate survival rate of patients who received $\mathrm{CPR}$, provided to the public by the medical dramas was over-optimistic [10]. However, three other studies conducted to evaluate the CPR survival rates shown in television medical dramas failed to identify significant differences from the survival rates provided in the literature [11-13]. The findings of the present study, based on newspapers and Internet web pages, are consistent with Diem and colleagues' findings from television medical dramas, in that medical information provided by newspapers and the Internet to the public is over-optimistic as indicated by the survival rate of the patients sustained using LST, and may mistakenly convince the public that an aggressive LST (such as CPR and ECMO) can rescue patients from all life-threatening conditions. Although the portrayal of the survival of patients receiving aggressive LST on television medical dramas remains controversial, it is apparent that such media outlets can substantially influence the public [14-17].

A study by Moynihan et al. investigated the coverage of three medications in the US news, observing that $60 \%$ of the news stories reported the potential benefits of the medications, whereas $47 \%$ of the news stories reported the potential harms. The study concluded that the coverage of the three drugs focused predominantly on their benefits [18]. Bartlett et al. reported that medical journals generally provide equal coverage of the positive and negative results of medical research, whereas newspapers are more likely to publish the negative results [19]. For example, one study concluded that jogging is significantly associated with beneficial effects on health [20] and another study showed that the risk of acute myeloid leukemia is significantly increased in cockpit crews [21].
Newspapers would tend to report the results of the second study rather than the first. Our study results showed that the survival rate of the 60 patients in newspapers and 182 stories in newspapers were both significantly higher than the average survival rates in the four ECMO studies in Taiwan, which suggested that newspapers are likely to provide over-optimistic medical information on ECMO use as a LST.

For ECMO use shown on the Internet web pages, we found two ways that the medical information was overoptimistic: First, writers or bloggers of Internet web pages were more likely to select the alive ECMO users than the dead, as indicated by the significantly higher survival rate of the 55 patients on the Internet than the highest survival rates of ECMO use $(p=.01)$ in the four studies in Taiwan; Second, writers or bloggers were more likely to reproduce or duplicate the alive ECMO users shown by other Internet web pages than the dead ECMO users, as indicated by the higher survival rate of the 237 stories on the Internet than that of the 55 patients on the Internet $(p=.31)$. Writers or bloggers of the Internet web pages may not have particular interests in reporting, reproducing or duplicating optimistic outcomes of ECMO use. Instead, they may report, reproduce or duplicate stories of their own personal interests or those which are effective in attracting readers' attention.

Medical decisions to request aggressive LST is frequently discussed in the field of medical ethics. Physicians assist with a patient's or family member's medical decision-making by providing medical information and suggestions based on scientific and humanistic principles, and with respect for patient autonomy. Patients usually make medical decisions depending on the medical information and suggestions given by the physicians, personal values, personal preferences, and past medical experiences [22]. Therefore, the over-optimistic survival rate of ECMO users reported by the newspaper articles and Internet web pages may potentially influence patients' and family members' personal values and personal preferences, thus encouraging them to request ECMO being performed on themselves or their relatives while death is imminent.

None of the laws associated with clinical practice in Taiwan (e.g., Physicians Act [23], Medical Care Act [24], Hospice Palliative Care Act [25]) forces physicians to provide aggressive LST which is considered inappropriate to patients even if patients/family members request them. Therefore, physicians theoretically can decline the request of inappropriate LST based on their professional judgment. However, if the family members are influenced by the over-optimistic survival rate of the inappropriate LST users reported in newspaper articles and Internet web pages, and thus strongly request the inappropriate LST to be performed on the patients, 
physicians, usually in fear of litigation or the burdensome process of litigation [26,27], are more likely to perform that LST without carefully deliberating its clinical indications.

\section{Strengths and limitations}

This study evaluated the medical information on ECMO use presented in newspaper articles and Internet web pages. According to the 2010 Annual Report of Mass Media by Shih Hsin University College of Journalism and Communications [28], 97.3\%, 74\%, and $71.3 \%$ of adults in Taiwan, aged between 15 and 64, acquired health-related information by watching television, reading newspapers, and searching the Internet, respectively. Readers of the Liberty Times, the Apple Daily, the United Daily News, and the China Times constituted 16.9\%, 15.9\%, 7.7\%, and $6.1 \%$ of Taiwanese people who read newspapers, respectively [29]. Medical information on ECMO use in the four major newspapers and on Internet web pages may, thus, influence a large proportion of the Taiwanese population.

Our study has two major limitations. First, our results might not be applicable to other newspapers in Taiwan and elsewhere in the world, or to other Internet web pages not using traditional Chinese language. Second, we obtained our data for analyses from newspapers in Taiwan and the Internet web pages. The stories of ECMO use reported by newspaper articles and Internet web pages might not contain all the variables we needed in this study. Therefore, some variables in this study inevitably had missing values.

\section{Conclusions}

Newspapers and the Internet have the potential to influence patients' knowledge and attitudes toward medical decisionmaking by providing over-optimistic medical information through the following ways: First, the mass media tend to attract the public's attention by reporting the positive outcome of an important breakthrough in clinical medicine; Second, the mass media tend to report patients who survive to hospital discharge, rather than those who die during hospital stay; Third, the survived patients and their stories are more likely to be duplicated in newspapers and on Internet web pages than those who die during hospital stay. Newspaper readers and Internet users may, therefore, mistakenly believe that ECMO can usually rescue patients from all lifethreatening conditions. However, ECMO, similar to other aggressive LST such as CPR, is ethically appropriate to be initiated on patients with reversible diseases, not on those with irreversible diseases. Future research should examine the influence of the over-optimistic information provided by the two means of mass media on medical decisionmaking for requesting aggressive LST such as ECMO use, as well as the attitudes physicians have toward the use of inappropriate LST requested by patients with overoptimistic information provided via mass media.

\section{Abbreviations}

CPR: Cardiopulmonary resuscitation; ECMO: Extra-corporeal membrane oxygenation; ECLS 2014: Extracorporeal Life Support Registry Report International Summary for January 2014; LST: Life-supporting treatments.

\section{Competing interests}

The authors declare that they have no competing interests.

\section{Authors' contributions}

YC (Chen YY) carried out the literature review, study design, statistical analyses, manuscript drafting, and manuscript editing. LC (Chen L) carried out the statistical analyses and manuscript editing. YK (KaO YH) helped with the literature review, data collection and data comparison. TC (Chu TS) helped with manuscript editing. TH (Huang TS) helped with study design and manuscript editing. WK (Ko WJ) participated in manuscript editing. All authors read and approved the final manuscript.

\section{Acknowledgement}

The authors would like to thank Taiwan Ministry of Science and Technology (99-2511-S-002-003-MY2 and 101-2511-S-002-010-MY3) and National Taiwan University Hospital (103-N2590) for partly supporting this study.

\section{Financial support information}

This study was partly supported by research grants from Taiwan Ministry of Science and Technology (99-2511-S-002-003-MY2 and 101-2511-S-002-010-MY3) and National Taiwan University Hospital (103-N2590).

\section{Author details}

${ }^{1}$ Department of Social Medicine, National Taiwan University College of Medicine, No. 1, Rd. Ren-Ai sec. 1, Taipei 10051, Taiwan. ${ }^{2}$ Department of Medical Education, National Taiwan University Hospital, No. 7, Rd. Chong-Shan S, Taipei 10002, Taiwan. ${ }^{3}$ Institute of Population Health Sciences, National Health Research Institutes, 35 Keyan Road, Zhunan, Miaoli County 35053, Taiwan. ${ }^{4}$ Department of Sociology, lowa State University, 103 East Hall, Ames, IA 50011, USA. ${ }^{5}$ Department of Primary Care Medicine, National Taiwan University College of Medicine, No. 1, Rd. Ren-Ai sec. 1, Taipei 10051, Taiwan. ' Department of Internal Medicine, National Taiwan University Hospital, No. 7, Rd. Chong-Shan S, Taipei 10002, Taiwan. ${ }^{7}$ Department of Surgery, National Taiwan University College of Medicine, No. 1, Rd. Ren-Ai sec. 1, Taipei 10051, Taiwan. ${ }^{8}$ Department of Traumatology, National Taiwan University Hospital, No. 7, Rd. Chong-Shan S, Taipei 10002, Taiwan.

Received: 11 October 2013 Accepted: 10 July 2014

Published: 1 August 2014

\section{References}

1. Extracorporeal Life Support Organization: Extracorporeal Life Support (ECLS) Registry Report International Summary. Ann Arbor, MI: Extracorporeal Life Support Organization; 2014.

2. Taiwan Department of Health: In: News of the Messenger. Taiwan: Taiwan Department of Health; 2010.

3. Ko WJ, Lin CY, Chen RJ, Wang SS, Lin FY, Chen YS: Extracorporeal membrane oxygenation support for adult postcardiotomy cardiogenic shock. Ann Thorac Surg 2002, 73(2):538-545.

4. Hsu PS, Chen JL, Hong GJ, Tsai YT, Lin CY, Lee CY, Chen YG, Tsai CS: Extracorporeal membrane oxygenation for refractory cardiogenic shock after cardiac surgery: predictors of early mortality and outcome from 51 adult patients. Eur J Cardiothorac Surg 2010, 37(2):328-333.

5. Chou NK, Chi NH, Wu IW, Huang SC, Chen YS, Yu HY, Tsao Cl, Ko WJ, Chu SH, Wang SS: Extracoporeal membrane oxygenation to rescue cardiopulmonary failure after heart transplantation: a single-center experience. Transplant Proc 2010, 42(3):943-945.

6. Chen YC, Tsai FC, Chang CH, Lin CY, Jenq CC, Juan KC, Hsu HH, Chang MY, Tian YC, Hung CC, Fang JT, Yang CW: Prognosis of patients on extracorporeal membrane oxygenation: the impact of acute kidney injury on mortality. Ann Thorac Surg 2011, 91(1):137-142.

7. Hsu KH, Chi NH, Yu HY, Wang CH, Huang SC, Wang SS, Ko WJ, Chen YS: Extracorporeal membranous oxygenation support for acute fulminant myocarditis: analysis of a single center's experience. Eur J Cardiothorac Surg 2011, 40(3):682-688. 
8. Chung SY, Sheu JJ, Lin YJ, Sun CK, Chang LT, Chen YL, Tsai TH, Chen CJ, Yang CH, Hang CL, Leu S, Wu CJ, Lee FY, Yip HK: Outcome of Patients With Profound Cardiogenic Shock After Cardiopulmonary Resuscitation and Prompt Extracorporeal Membrane Oxygenation Support. Circ J 2012, 76(6):1385-1392.

9. Chen YY, Chen L, Huang TS, Ko WJ, Ni YH, Chang SC: Significant social events and increasing use of life-sustaining treatment: trend analysis using extracorporeal membrane oxygenation as an example. BMC Medical Ethics 2014, 15:21.

10. Diem SJ, Lantos JD, Tulsky JA: Cardiopulmonary resuscitation on television, Miracles and misinformation. N Engl J Med 1996, 334(24):1578-1582.

11. Gordon PN, Williamson S, Lawler PG: As seen on TV: observational study of cardiopulmonary resuscitation in British television medical dramas. BMJ 1998, 317(7161):780-783.

12. Van den Bulck J, Damiaans K: Cardiopulmonary resuscitation on Flemish television: challenges to the television effects hypothesis. Emerg Med J 2004, 21(5):565-567.

13. Harris $D$, Willoughby $H$ : Resuscitation on television: realistic or ridiculous? A quantitative observational analysis of the portrayal of cardiopulmonary resuscitation in television medical drama. Resuscitation 2009, 80(11):1275-1279.

14. Gibbon JH Jr: The development of the heart-lung apparatus. Am J Surg 1978, 135(5):608-619.

15. Gibbon JH Jr: Memoir of J. Parsons Schaeffer 1878-1970. Trans Stud Coll Physicians Phila 1971, 38(4):249-251.

16. Moynihan R, Bero L, Ross-Degnan D, Henry D, Lee K, Watkins J, Mah C, Soumerai SB: Coverage by the news media of the benefits and risks of medications. N Engl J Med 2000, 342(22):1645-1650.

17. Baer NA: Cardiopulmonary resuscitation on television, Exaggerations and accusations. N Engl J Med 1996, 334(24):1604-1605.

18. The collaborative UK ECMO (Extracorporeal Membrane Oxygenation) trial: follow-up to 1 year of age. Pediatrics 1998, 101(4):E1.

19. Bartlett C, Sterne J, Egger M: What is newsworthy? Longitudinal study of the reporting of medical research in two British newspapers. BMJ 2002, 325(7355):81-84

20. Schnohr P, Parner J, Lange P: Mortality in joggers: population based study of 4,658 men. BMJ 2000, 321(7261):602-603.

21. Gundestrup M, Storm HH: Radiation-induced acute myeloid leukaemia and other cancers in commercial jet cockpit crew: a population-based cohort study. Lancet 1999, 354(9195):2029-2031.

22. Brett AS: Inappropriate requests for treatments and tests. In 20 COMMON PROBLEMS-Ethics in Primary Care. Edited by Sugarman J. New York: The McGraw-Hill Companies, Inc; 2000:3-12.

23. Laws \& Regulations Database of the Republic of China: Physicians Act. http://law.moj.gov.tw/Eng//LawClass/LawContent.aspx?pcode=L0020001 (Accessed on June 16, 2014).

24. Laws \& Regulations Database of the Republic of China: Medical Care Act. http://law.moj.gov.tw/Eng/LawClass/LawContent.aspx?PCODE=L0020021 (Accessed on June 16, 2014).

25. Laws \& Regulations Database of the Republic of China: Hospice Palliative Care Act. http://law.moj.gov.tw/Eng/LawClass/LawContent.aspx? PCODE=L0020066 (Accessed on June 16, 2014).

26. Roy AD, Chen L, Santucci K: What do pediatric residents know about malpractice? Pediatr Emerg Care 2011, 27(7):586-590.

27. Burkle $C M$, Martin DP, Keegan MT: Which is feared more: harm to the ego or financial peril? A survey of anesthesiologists' attitudes about medical malpractice. Minn Med 2012, 95(9):46-50.

28. Shih Hsin University College of Journalism and Communications: The 2010 Annual Report of Mass Media. http://www.shadowgov.tw/41299_0 is.htm (Accessed on June 16, 2014).

29. The Liberty Times: The Audit Bureau of Circulation audited the circulation in March 2010. http://www.libertytimes.com.tw/2010/new/may/25/today-life1. htm (Accessed on June 16, 2014)

doi:10.1186/1472-6939-15-59

Cite this article as: Chen et al:: The over-optimistic portrayal of life-supporting treatments in newspapers and on the Internet: a cross-sectional study using extra-corporeal membrane oxygenation as an example. BMC Medical Ethics 2014 15:59.

\section{Submit your next manuscript to BioMed Central and take full advantage of:}

- Convenient online submission

- Thorough peer review

- No space constraints or color figure charges

- Immediate publication on acceptance

- Inclusion in PubMed, CAS, Scopus and Google Scholar

- Research which is freely available for redistribution

Submit your manuscript at www.biomedcentral.com/submit
() Biomed Central 